\title{
REVIEW
}

\section{Biological production of the oceans: the case for a consensus}

\author{
Trevor Platt ${ }^{1}$, William G. Harrison ${ }^{1}$, Marlon R. Lewis ${ }^{2}$, William K. W. Li $^{1}$, Shubha \\ Sathyendranath ${ }^{2}$, Ralph E. Smith ${ }^{1,3}$, Alain F. Vezina ${ }^{1,4}$ \\ ${ }^{1}$ Biological Oceanography Division, Bedford Institute of Oceanography, Dartmouth, Nova Scotia, Canada B2Y 4A2 \\ ${ }^{2}$ Department of Oceanography, Dalhousie University, Halifax, Nova Scotia, Canada B3H 4J1 \\ ${ }^{3}$ Biology Department, University of Waterloo, Waterloo, Ontario, Canada N2L 3G1 \\ ${ }^{4}$ Université du Québec à Rimouski, Rimouski, Québec, Canada G5L 3A1
}

\begin{abstract}
Biological dynamics in the pelagic ocean are intermittent rather than steady. In oceanic regimes, where nitrogen is limiting to phytoplankton growth, an important fraction of the annual, primary production depends on transient episodes of increased nitrate supply: at such times the role of locally-regenerated nitrogen is correspondingly less. Proper averaging of these variable rates, in time and space, is the key to reconciliation of existing data on the biogenic fluxes of oxygen and carbon in the ocean. The magnitude of oceanic production supported by nitrate (the new production) is higher than previously thought.
\end{abstract}

In the oceans, as on the land, the fundamental biological process is photosynthetic fixation of carbon. In ecological terminology, the rate of photosynthesis is called the primary production. Notwithstanding that it is the principal source of organic carbon for the support of the entire marine ecosystem, the magnitude of primary production in the ocean is still disputed to within a factor of 10 (Eppley 1980, Shulenberger \& Reid 1981, Jenkins 1982a, Williams et al. 1983, Platt 1984, Platt \& Harrison 1985, Platt \& Harrison 1986, Reid \& Shulenberger 1986). The disagreement is most acute for the open ocean, which comprises $90 \%$ of the surface area of the world ocean, and accounts for more than $80 \%$ of marine biological production on a global scale. Although the debate has animated important research on the major biogeochemical cycles of the oceans (National Academy of Sciences 1984), the uncertainty continues to confound speculation on such important questions as whether ocean phytoplankton will serve as a significant sink for the $\mathrm{CO}_{2}$ that is building up in the atmosphere (Sarmiento \& Toggweiler 1984). It is argued here that the divergent points of view can be reconciled within the resolution of the existing data: a consensus is emerging. The common ground, however, relates to the new production (sensu Dugdale \& Goering 1967) rather than the total primary production.

\section{CONCEPTUAL BACKGROUND \\ Components of the carbon cycle}

The absolute fixation rate of inorganic carbon into organic molecules is the gross primary production $\left(P_{g}\right)$. When corrected for the respiration of the autotrophs $(R), P_{g}$ reduces to the net primary production $\left(P_{n}\right)$ :

$$
P_{g}-R=P_{n}
$$

These formal distinctions have no exact operational counterparts in work on natural communities (Table 1). A major complication is that microheterotrophs coexist with and share the same size range as autotrophs, and in seeking to measure the biomass or metabolism of the one it is exceptionally difficult to discriminate the biomass or metabolism of the other (Li 1986). Another complication is that it is often difficult, in respect of the autotrophs themselves, to specify, or control, the degree to which $R$ influences the measurement of $P$. The extent 
Table 1 Methods for estimating primary production in the ocean and the nominal time-scales on which the results apply. The components $P_{g}, P_{n}$, and $P_{c}$ of primary production refer to a scheme based on carbon; $P_{T}$ and $P_{\text {new }}$ to one based on nitrogen. Sedimentation rate refers to the gravitational flux of organic particles leaving the photic zone, not the (much smaller) flux arriving at the sediment surface. See also Fig. 1

\begin{tabular}{|c|c|c|}
\hline Method & $\begin{array}{l}\text { Nominal component of } \\
\text { production }\end{array}$ & Nominal time-scale \\
\hline \multicolumn{3}{|l|}{ In vitro } \\
\hline${ }^{14} \mathrm{C}$ assimilation & $P_{T}\left(\equiv P_{n}\right)$ & Hours to $1 \mathrm{~d}$ (duration of incubation) \\
\hline $\mathrm{O}_{2}$ evolution & $P_{T}$ & Hours to $1 \mathrm{~d}$ (duration of incubation) \\
\hline${ }^{15} \mathrm{NO}_{3}$ assimilation & $P_{\text {new }}$ & Hours to $1 \mathrm{~d}$ (duration of incubation) \\
\hline \multicolumn{3}{|l|}{ Bulk property } \\
\hline Sedimentation rate below photic zone & $P_{\text {new }}\left(\equiv P_{c}\right)$ & Days to months (duration of trap deployment) \\
\hline Oxygen utilization rate OUR & $P_{\text {new }}$ & Seasonal to annual \\
\hline Net $\mathrm{O}_{2}$ accumulation in photic zone & $P_{\text {new }}$ & Seasonal to annual \\
\hline $\mathrm{NO}_{3}$ flux to photic zone & $P_{\text {new }}$ & Hours to days \\
\hline \multicolumn{3}{|l|}{ Upper limit } \\
\hline $\begin{array}{l}\text { Optimal energy conversion of photons absorbed } \\
\text { by phytoplankton pigments }\end{array}$ & $P_{T}$ & Instantaneous to annual \\
\hline \multicolumn{3}{|l|}{ Lower limit } \\
\hline $\begin{array}{l}\text { Depletion of winter accumulation of } \mathrm{NO}_{3} \text { above } \\
\text { seasonal thermocline }\end{array}$ & $P_{\text {new }}$ & Seasonal \\
\hline
\end{tabular}

of the resulting bias in particular cases will depend on the structure (topology) of the local food web and on the measurement techniques employed (Eppley 1980, Peterson 1980, Smith et al. 1984). If the respiration of all heterotrophs (both macroscopic and microscopic) in the community is subtracted from $P_{R}$, the residual is called the net community production $\left(P_{\mathrm{c}}\right)$.

\section{Components of the nitrogen cycle}

The limiting elemental resource for plant production in most oceanic regions is believed to be nitrogen (Carpenter \& Capone 1983), which may be supplied in various chemical forms from a variety of sources. Another way to partition the primary production then is according to the source and oxidation state of the nitrogen substrates utilised (Dugdale \& Goering 1967). Strictly, the partition depends on whether the nitrogen is supplied by regeneration from organisms within the euphotic zone (regenerated production, $P_{I}$ ) or from outside the photic zone (new production, $P_{n e w}$ ). In the open ocean, the dominant contribution to externallysupplied nitrogen is the vertical flux in the form of nitrate (Eppley et al. 1973, Fogg 1982), whereas regenerated production depends only on reduced nitrogen compounds, in particular ammonia. It is therefore conventional to equate new production with nitrate-based production. (Any nitrogen supplied by horizontal advection or terrestrial runoff, whether oxidized or reduced, or from the atmosphere by direct fixation or washout from rain, would be included in the new production.) Other parts of the nitrogen cycle, such as nitrification (a component of regenerated production) and denitrification, are considered to be relatively unimportant in the photic zone. The sum of $P_{\text {new }}$ and $P_{r}$ is referred to as the total production $P_{T}$. The ratio $P_{n e w} /$ $P_{T}$ is called the $f$-ratio (Eppley \& Peterson 1979). Total production, $P_{T}$, is the nitrogen-equivalent of $P_{g}$, in the sense that it represents the sum total of nitrogen assimilation by the photoautotrophs. However, because there is no evidence that phytoplankton remineralise nitrogen, a case could be made for equating $P_{T}$ with $P_{n}$. The distinction is of significance for calculations involving the interconversion of carbon and nitrogen. It is conventional to convert between carbon and nitrogen using stoichiometric factors known as the Redfield ratios (Redfield et al. 1963, Takahashi et al. 1985). We follow the same convention in this paper, in which case it is appropriate to consider $P_{T}$ equivalent to $P_{\Omega}$ (Lancelot \& Billen 1985).

Many of the arguments that follow rest on the (idealised) premise that the pelagic zone of the ocean is in a biochemical steady state (Fig. 1). Then, the flux of nitrogen leaving the photic zone in sedimenting biogenic particles is balanced by the vertical flux of nitrate into the zone. In principle, if there were no leakage of nitrogen, the pelagic ecosystem could run indefinitely on regenerated nitrogen alone. There is always, however, a constant nitrogen loss through gravitational settling of organic material or otherwise. (In areas subject to heavy exploitation of renewable resources, a potentially significant loss is that associated with the harvest of fish.) If the nitrogen losses 


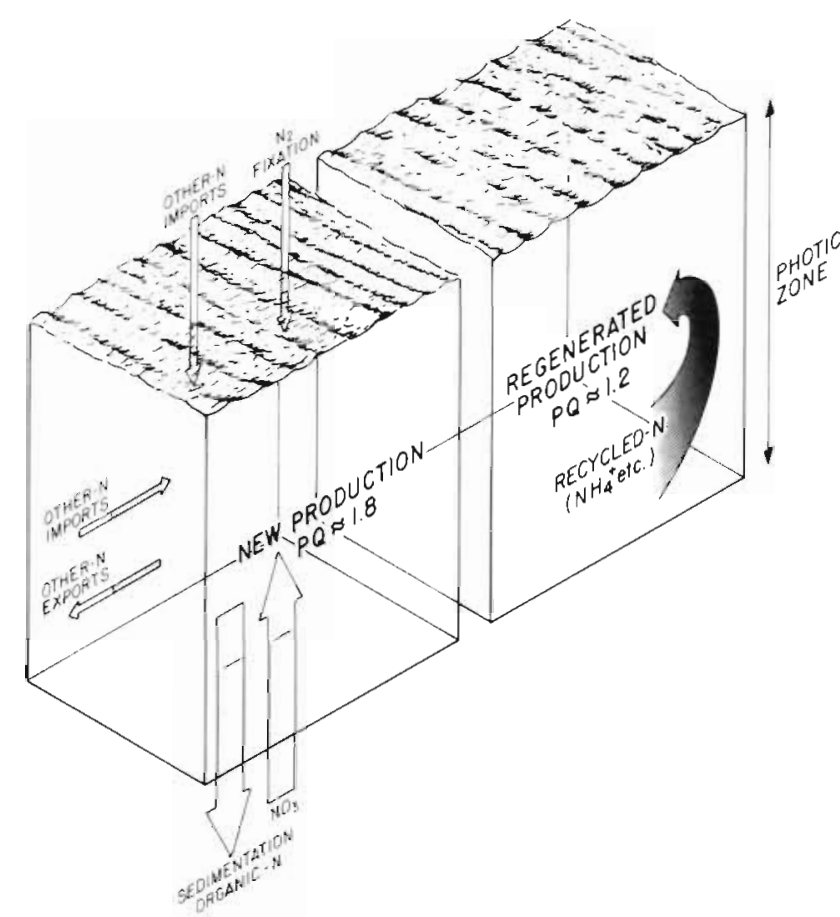

Fig. 1. Schematic of principal fluxes for new and regenerated production. The sole support for regenerated production is reduced nitrogen supplied within the photic zone by the excretion of organisms. New production depends on nitrogen supplied from outside the photic zone, of which the dominant flux is the delivery of nitrate from below. In the steady state this vertical flux is balanced by the downward flux of nitrogen in the sedimenting particles. At the annual time-scale, current evidence is that in the open ocean, new production is very roughly from one third to one half of regenerated production, but may deviate considerably from this figure over short timeand space-scales

were not replaced in the form of nitrate, the pool of nitrogen available to run the regenerated production cycle would become depleted. The new production, and its equivalent nitrate flux, may be thought of as the maximum rate at which organic compounds can be extracted from the photic zone without jeopardy to the long-term integrity of the ecosystem contained therein. In other words (Platt et al. 1984), for the long term, $P_{\text {new }}$ is synonymous with $P_{c}$.

\section{SCALES OF MEASUREMENT FOR PRIMARY PRODUCTION}

We may distinguish 2 kinds of index for primary production (Table 1). Incubation in vitro (seawater samples containing natural phytoplankton assemblages at natural concentrations, contained in bottles) provides one such index of photosynthetic rate. For example, the assimilation of carbon may be measured by uptake of the tracer ${ }^{14} \mathrm{C}$; the evolution of oxygen by direct titration. Changes in the bulk properties of the water column give other indices of primary production. They include the change in dissolved $\mathrm{O}_{2}$ content of the photic zone, the rate of sedimentation of organic particles, the consumption of $\mathrm{O}_{2}$ below the photic zone by the decomposition of the sedimenting material (the oxygen utilization rate, OUR), and the vertical flux of nitrate into the photic zone (Platt et al. 1984).

It is crucial to realize that these various methods do not all refer to the same component of primary production. Nor do they all refer to the same fundamental timescale (Table 1). That is to say, each method may be characterized by an intrinsic timescale to which its results apply, but outside of which they may be invalid. The reason is that primary production is very far from constant in space and time, so that the way it is averaged has a profound effect on the results (Platt \& Harrison 1985). When incubations to determine $P_{T}$ are of duration less than $1 \mathrm{~d}$, extrapolation of the results to daily rates is fraught with difficulty. Generally, measurements based on changes in the bulk properties of the water column refer to a longer timescale than do in vitro ones. They also depend more heavily on the assumption of biochemical steady state for the photic zone. A further complication is that the basic dimensions of the results may differ. In vitro estimates refer to discrete depths and fluxes per unit volume, whereas bulk property methods require averaging over depth, and therefore refer to fluxes per unit area of sea surface.

\section{COMPARING INDICES OF PRIMARY PRODUCTION}

Because the ocean is undersampled with respect to primary production measurements, we should attempt to assemble all relevant data into a single data base, after intercomparison of different techniques. But the incompatibility of intrinsic timescales, and the difficulty of extrapolating one component of primary production to estimate another, limit the resolving power of the comparison. The temptation to extrapolation may be irresistible, but the results will not be robust unless all the processes linking the 2 scales of event are understood in detail, which they are clearly not in this case.

Of course, comparisons have been, and will continue to be, made between the various indices of primary production. Inconsistencies have been reported: they may be classified into 2 groups (Platt \& Harrison 1986). In the first, which we may call Hypothesis I, indices of $P_{\text {new }}$ (Table 1) are held to exceed in vitro measurements of $P_{r}$. This is a serious claim, and if supported would subsume the weaker, Hypothesis II that bulk estimates of $P_{\text {new }}$ (Table 1), when extrapolated to $P_{Y}$, exceed in vitro measures of $P_{T}$. Given that $P_{T}$ is usually measured 
by assimilation of ${ }^{14} \mathrm{CO}_{2}$, the hypotheses are often stated, implicitly or explicitly, in terms of the ${ }^{14} \mathrm{C}$ method versus methods based on changes in bulk properties. We now examine the hypotheses, but do not discuss the technicalities of the ${ }^{14} \mathrm{C}$ method itself, which are outside the scope of this review (Peterson 1980). In testing the hypotheses we do not regard either side of the comparisons as an absolute standard: we look for agreement or otherwise within the errors of both.

\section{Hypothesis I}

Shulenberger \& Reid (1981) supported Hypothesis I for the central North Pacific. Increase in the $\mathrm{O}_{2}$ supersaturation (roughly $8.5 \%$ ) just below the seasonal thermocline between spring and summer was used as an estimate of $P_{c}$. The primary production that would be required to generate this much oxygen appeared to be higher than indicated by the in vitro measurements. Platt (1984) considered that the excess oxygen due to photosynthesis had been overestimated. Reid \& Shulenberger (1986) disputed this view. Subsequently, using an independent method, it was shown (Craig \& Hayward 1987) that air injection would contribute $1.5 \%$ to the oversaturation and thermodynamic corrections a further $1.5 \%$. The mean oversaturation due to biological processes (Craig \& Hayward 1987) was $(6.0$ $\pm 0.62) \%$, close to the value $(5.5 \%)$ used by Platt (1984) to show that the oxygen results were not significantly higher than the ${ }^{14} \mathrm{C}$ results within the resolution of the data. Moreover, given that the $\mathrm{O}_{2}$ excess represents $P_{c}$, it should be converted to carbon (Platt \& Harrison 1986) through a photosynthetic quotient of 1.8 rather than the conservative 1.0 used in Platt (1984), further increasing the carbon-based rates relative to the oxygen-based ones. Thus, although unexpectedly high new production is implied, the evidence of the central North Pacific is not sufficient to support Hypothesis I.

In extrapolation of in vitro estimates for comparison with bulk property estimates, it is usually assumed that the fluxes are constant in time and uniform over very large areas of the ocean. The bulk property estimates for a particular location are often compared, unjustifiably, with in vitro estimates averaged over entire ocean basins. Hypothesis I was supported for a region of the subtropical North Atlantic (Jenkins 1982a) for which no local ${ }^{14} \mathrm{C}$ data were cited. The standard of comparison used was the global mean production rate for the oligotrophic oceans (Koblentz-Mishke et al. 1970, as cited in Menzel 1974): the value of $P_{T}$ was inappropriate as a yardstick for $P_{\text {new. }}$. No evidence has been produced for the North Atlantic that compels us to support Hypothesis I.

\section{The f-ratio and Hypothesis II}

Invoking Hypothesis II requires application of the identity $P_{T}=(f)^{-1} P_{\text {new }}$, to extrapolate estimates of $P_{\text {new }}$ to $P_{T}$. The $f$-ratio is thus cast in a role of central importance. Conventionally, $f$ is measured by assimilation of ${ }^{15} \mathrm{~N}$, in the form of nitrate or ammonia, during incubation in vitro (Eppley \& Peterson 1979). So measured, $f$ has an intrinsic timescale of hours: it is inappropriate as a divisor for bulk property estimates of $P_{\text {new }}$ (time-scale of weeks to years) unless it can be shown that $f$ is uniform everywhere within the spatial domain defined by the characteristic timescale of $P_{\text {new }}$, and constant over the same time-scale. Because $f$ depends on the local nitrate supply and also responds to changes in the structure and dynamics of the local food web, the probability of its being a universal constant is remote. We are therefore led to define a similar ratio, $\langle f\rangle$, with a longer characteristic time-scale:

$$
<f>=\iint P_{\text {new }} \mathrm{d} z \mathrm{~d} t / \iint P_{T} \mathrm{~d} z \mathrm{~d} t
$$

where the integrals are taken through the photic zone and over the seasonal or longer time period. Eq. (2) can be evaluated from a time series for $f$, provided that the covariance of $P_{T}$ and $f$ is taken into account (Platt \& Harrison 1985, Vezina \& Platt 1987).

The value $\langle f\rangle=0.1$ for the oligotrophic ocean, suggested in the seminal paper by Eppley \& Peterson (1979), has sometimes been used uncritically by subsequent authors. In fact, in no oligotrophic ocean do time series exist for $f$, measured directly in vitro, that would allow calculation of $\langle f\rangle$ at the seasonal or annual time-scale. However, it may be possible under certain circumstances to estimate $f$ from ambient nitrate, or nitrate and ammonia, concentrations (Platt \& Harrison 1985, Harrison et al. 1987), and time series data do exist for at least one open ocean location, Station $\mathrm{S}$ in the Sargasso Sea. Analysis of these data suggests that, instantaneously, $f$ may take values in the range from 0 to 0.8 , and that $\langle f\rangle=0.3$ at the annual scale.

The algorithm to estimate $f$ from ambient nitrate concentration (Platt \& Harrison 1985) was established originally using data from coastal and continental shelf waters, and can be criticized for this reason in its application to the open ocean (Le Bouteiller 1986) or in ocean regions where primary production may not be limited by nitrogen (Dugdale 1986). However, the annual range of nitrate values in the Station $\mathrm{S}$ data set is similar to that observed in coastal waters. Furthermore, new data from the oligotrophic North Atlantic, west of the Azores, lead to the same general conclusions (Lewis et al. 1986, Harrison et al. 1987). Direct measurements of $f$ by ${ }^{15} \mathrm{~N}$ uptake at this open-ocean station were shown to depend on ambient nitrate in a similar way as at stations close to shore. The magnitude of $f$ was consistent 
with simultaneous estimates of the vertically-diffusive nitrate flux made from measurements of the local, vertical gradient of nitrate and highly-resolved measurements of velocity shear (Oakey 1982).

Because nitrogen-limited systems are usually responsive to local increases in nitrate supply, one should look to instances where these may occur for direct evidence of temporal fluctuations in $f$ (as measured by ${ }^{15} \mathrm{~N}$ ) and their correlation with $P_{\Upsilon}$. For example, in the warm-core rings of the Gulf Stream, Sargasso Sea water is carried north into the cooler Slope Water. Recent work on the ageing of such rings (McCarthy \& Nevins 1986) shows that the typical value of $f$ at the time of separation of the ring from the Gulf Stream is 0.13 , rising to 0.32 in a ring 3 mo old, presumably due to increased vertical nitrate flux associated with convective mixing. The phytoplankton response to frictional decay of a warm-core ring has been modelled (Franks et al. 1986): it is found that relaxation of the ring causes upward motion of nutrient-rich water leading to a value of 0.2 for $f$ at the ring center. Following the passage of a storm, it was observed (McCarthy \& Nevins 1986) that deepening of the thermocline inside a ring raised $f$ from 0.32 to 0.52 . The effect of storm passage would not be confined to the waters inside the ring, but would be a general phenomenon within the area affected by the storm (Iverson 1977). Further evidence exists for 'atypically' high $f$ values in the Sargasso Sea. From changes over $5 \mathrm{~d}$ during June in the nitrate content of the upper $30 \mathrm{~m}$ of the water column at the center of a warm-core ring (Garside 1985), the nitrate-based production was calculated to be about $0.5 \mathrm{~g} \mathrm{C} \mathrm{m}^{-2} \mathrm{~d}^{-1}$. Comparison with $P_{r}$ measured by ${ }^{14} \mathrm{C}$ uptake implied $f>0.5$.

It could be argued that citing data from ring and eddy studies distorts the true picture, an argument that would be tenable if eddies were few and far between, and if $f$ and $P_{T}$ did not covary. In physical oceanography, however, a picture is emerging in which the ocean is replete with mesoscale eddies (Kerr 1985). Their significance for the oceanography of the Mediterranean and other seas and oceans has recently been emphasized (Robinson et al. 1987). An intense cold-core eddy, analogue of the cold-core Gulf Stream rings known in the Northwest Atlantic, has been observed in the Northeast Atlantic (Kupferman et al. 1986). Over the North Atlantic, the distribution of eddy-scale kinetic energy indicates variability associated with features of characteristic size of order $100 \mathrm{~km}$, such as warm-core rings and meanders in western boundary currents. Maps of eddy kinetic energy derived from SEASAT altimeter data show high variance in a band from Cape Hatteras to the Grand Banks, and extending halfway across the ocean (Cheney et al. 1983 Menard 1983). Similar features are found in the North Pacific and in the western South Atlantic: they correspond to patterns already inferred from ships drift
(Wyrtki et al. 1976). More importantly, the distribution of eddy potential energy in the ocean is variable at the same scales (Dantzler 1977, Emery 1983). Potential energy is associated with vertical displacement of isopycnals, and hence of nutrient distributions. Variance in wind stress on scales of a few days should also contribute to vertical displacements of scalar fields as well as to cross-isopycnal mixing. Jenkins (1988) has emphasised the intermittency of nitrate supply to the euphotic zone in the North Atlantic near Bermuda. Entrainment of nitrate into the surface layer by wind, and its subsequent utilisation by phytoplankton, has been observed directly at sea in the Southern California Bight (Eppley \& Renger 1988). An instance of episodic nitrate input leading to a phytoplankton bloom in the Sargasso Sea has been observed by ship (Glover et al. 1988). A similar incident has been observed by remote sensing in the Mediterranean Sea (Lohrenz et al. 1988). We can therefore expect that locally-enhanced nitrate flux will not be an uncommon feature of the pelagic ocean. It is worthwhile, then, to anticipate how the ecosystem might respond.

Compartmental analysis of the pelagic food web (Vezina \& Platt 1987) is a useful technique to explore the consequences of transients in nitrate supply. A strictly linear model, where fluxes are directly proportional to the mass of material in the compartments, leads to the conclusion that ratio properties of the food web are uncorrelated with nitrate supply, because all fluxes are intensified by the same factor. In such a model, $f$ would be independent of $P_{T}$. But when nonlinear dynamics are admitted, in particular that the sedimentation flux increases faster than phytoplankton biomass (Vezina \& Platt 1987), it can be shown that $f$ depends on nitrate supply in a manner that resembles the empirical result (Platt \& Harrison 1985). Observational support for this formulation comes from numerical analysis of sediment trap data from the open ocean (Betzer et al. 1984). It is more plausible than the linear one in that it does not assume that the structure of the plankton community is constant in time nor uniform in space. An explicit expression for $f$ can be derived in terms of the flow structure of the pelagic food web (M. J. R. Fasham unpubl.).

The natural abundance of ${ }^{15} \mathrm{~N}$ in particles sinking in the ocean covaries with the magnitude of the particle flux, and provides a monitor for the nitrate flux into the photic zone during their formation (Altabet \& Deuser 1985), strengthening the argument that nitrate flux can be equated with sediment flux. In a 6 yr time series of sediment trapping in the Sargasso Sea, Deuser (1986) has confirmed the close coupling of sedimentation to primary production, extending results obtained earlier at the seasonal timescale in the North Atlantic (Deuser et al. 1981), Panama Basin (Honjo 1982), Black Sea (Izdar et al. 1984) and North Pacific (Honjo 1984). The inverse 
correlation between sediment flux and surface temperature 1 mo earlier is taken as evidence that the amount of material sinking is a response to vertical transport of nitrate (accompanied by surface cooling). Moreover, the organic carbon content of the sinking material is highest when the flux is highest. The implication is that recycling of carbon in the pelagic is less efficient at times of high production, in other words that $f$ and $P_{T}$ have positive covariance (Platt \& Harrison 1985). Food web analysis (Vezina \& Platt 1987) reproduces this result, and supports the empirical result of Eppley \& Peterson (1979) relating $f$ and $P_{T}$. The nonlinear dynamics reveal very clearly that the unweighted time average for $f$ can seriously underestimate $\langle f\rangle$. Thus, a simple mechanism in which changes in nutrient supply lead to significant changes in food web structure subsumes both the local and regional variability in the open ocean.

The evidence is accumulating, then, for local fluctuations in $f$, driven by intermittency in the physical forcing, leading to a value of $\langle f\rangle$ higher than previously supposed for the open ocean. After analyzing data on OUR from Station $S$ and finding a figure for $P_{\text {new }}$ higher than anticipated, Jenkins \& Goldman (1985) noted that a conventional extrapolation of $P_{\text {new }}$ to $P_{T}$, through a low and constant $f$, might lead to a value of $P_{T}$ favouring support of Hypothesis II. They also remarked that intermittency in the nitrate supply could render this procedure invalid. Platt \& Harrison (1985) shared the same point of view: using the figure for $\langle f\rangle$ derived from the time series of nitrate at Station $S$, they showed that the ${ }^{14} \mathrm{C}$ and OUR data could indeed be reconciled, such that Hypothesis II could be rejected in this test. These results are consistent with those in the later publication by Jenkins (1988), based on the relative concentration of ${ }^{3} \mathrm{He}$ in the mixed layer.

In a long-term sediment trap study (VERTEX) of the Northeast Pacific (Pace et al. 1987), <f> was found to vary in the range from 0.13 to 0.25 , with new production being higher than previously believed, but only one third of that recently reported for the oligotrophic Atlantic (Jenkins \& Goldman 1985). In the discussion of the VERTEX data, it has also been pointed out (Martin et al. 1987) that the OUR decreases more rapidly with depth in the North Pacific than in the Sargasso Sea, implying that transport of organic carbon along isopycnals into the area, below the photic zone, is not a negligible term in the carbon budget for the Sargasso Sea. Correcting for this advective term, new primary production in the oligotrophic North Atlantic would be more nearly equal to that in the North Pacific.

In a direct comparison of in vitro measures of new production against new production estimated from the biological component of oxygen oversaturation at Ocean Weather Station P in the subarctic Pacific, it was found (Emerson 1987) that the 2 sets of figures agreed within the limits of error. They were also within the range of independent estimates of new production calculated from summer nitrate depletion. Further, there was a 3-fold variation in the summer oxygen excess, and corresponding new production estimate, during the period 1969 to 1978 , the variation being larger than the yearly standard deviation. These results, as do those from the Atlantic (Jenkins 1982b), suggest that interannual variance may be appreciable, with implications for the concept of the pelagic ocean as a steady state system at the annual time-scale.

Because the dominant flux of new nitrogen in the open ocean has a preferred direction, we expect that the water column will be vertically structured with respect to the $f$-ratio, decreasing from the base of the photic zone towards the surface. Intuitively, one expects that this decrease should be gradual, but evidence has been provided from the North Pacific for the photic zone's being partitioned into 2 layers (Knauer et al. 1984). The lower layer, being closer to the nutrient source, is more representative of eutrophic conditions, while the upper layer has a higher recycling efficiency. This picture has received further support from measurements of the residence time of dissolved ${ }^{234} \mathrm{Th}$ at various depths in the photic zone (Coale \& Bruland 1987). The implication is that variation of $P_{\text {new }}$, stated explicitly in Eq. (2), should not be overlooked in the calculation of average $\langle f\rangle$. The degree of vertical structuring will depend on the local density profile: clearly, such a biological separation of layers can only be maintained if the photic zone is deeper than the mixed layer.

\section{ECOLOGICAL ENERGETICS}

Estimates of primary production must respect known limits on the efficiency of photosynthesis, setting an upper bound to the value of $P_{T}$ that can be extrapolated from a given $P_{\text {new }}$ (Platt et al. 1984). The calorific value $E_{T}$ of total production corresponding to a new production $P_{\text {new }}$ is

$E_{T}=12 \times 11.4 \times 10^{3}\left(\frac{P_{\text {new }}}{1.8}+\frac{P_{T}-P_{\text {new }}}{1.25}\right) \mathrm{cal} \mathrm{m}^{-2} \mathrm{yr}^{-1}$ (3)

where the factor 12 is the atomic weight of carbon; $11.4 \mathrm{cal}(\mathrm{mg} \mathrm{C})^{-1}$ is the caloric content of phytoplankton (Platt \& Irwin 1973); and 1.8 and 1.25 are the photosynthetic quotients for new and regenerated production respectively (Williams et al. 1979, Raine 1983, Platt et al. 1987). Note that $1 \mathrm{cal}=4.1868 \mathrm{~J}$.

To compute the efficiency of energy conversion, we should first recognize that in the ocean much of the available light is absorbed by the water itself and is unavailable for photosynthesis. If the biomass is distributed evenly in the water column, it can be shown 
(Platt et al. 1984) that the fraction $q$ absorbed by photosynthetic pigments is given by

$$
q=\left(\begin{array}{lll}
k_{c} & B
\end{array}\right)\left(k_{w}+k_{c} \quad B\right)^{-1}
$$

where $k_{c}=$ the specific absorption coefficient for chlorophyll in $\mathrm{m}^{2}$ ( $\left.\mathrm{mg} \mathrm{chl}\right)^{-1} ; B=$ pigment biomass in $m g \mathrm{chl} \mathrm{m} \mathrm{m}^{-3}$ and $k_{w}=$ the absorption coefficient of the water itself in $\mathrm{m}^{-1}$. For the open ocean, $k_{w}=0.03$ in the visible region (Jerlov \& Steemann Nielsen 1974). An average value (Morel \& Bricaud 1981) for $k_{C}$ is 0.04 . It remains to estimate $B$.

As an example, we calculate for the Sargasso Sea. The Station $\mathrm{S}$ data record shows that the average pigment concentration in the photic zone varies from about 0.08 to $0.8 \mathrm{mg} \mathrm{chl} \mathrm{m}^{-3}$. The unweighted mean for the data is $0.28 \mathrm{mg} \mathrm{chl} \mathrm{m}^{-3}$, corresponding to $q=0.27$ (dimensionless). The total incident radiation at Bermuda averages $1.3 \times 10^{9} \mathrm{cal} \mathrm{m}^{-2} \mathrm{yr}^{-1}$ of which roughly half, or $6.5 \times 10^{8} \mathrm{cal} \mathrm{m}^{-2} \mathrm{yr}^{-1}$, will be in the photosynthetically-active part of the spectrum (Sterrer et al. 1981). Multiplying this figure by $q$ we find $1.8 \times 10^{8} \mathrm{cal}$ $\mathrm{m}^{-2} \mathrm{yr}^{-1}$ absorbed by phytoplankton and available for photosynthesis. It is an absolute upper bound (minimizing the implied efficiency) in that no allowance is made for absorption by detrital suspensoids, nor for the intense absorption of the red wavelengths near the surface; that it represents all wavelengths in the visible spectrum, not just the energy-efficient ones (Lewis et al. $1985 \mathrm{a}, \mathrm{b}$ ); that absorption by phaeopigments (Tilzer 1983) has not been discounted; and that only in the linear, or low light, region of the photosynthesis-light curve is maximum efficiency attained.

Fig. 2, calculated using Eq. (3), shows how the implied conversion efficiency depends on $\langle f\rangle$ when $P_{\text {new }}=5 \mathrm{~mol} \mathrm{O} \mathrm{m}^{-2} \mathrm{yr}^{-1}$. Note that conversion effi-

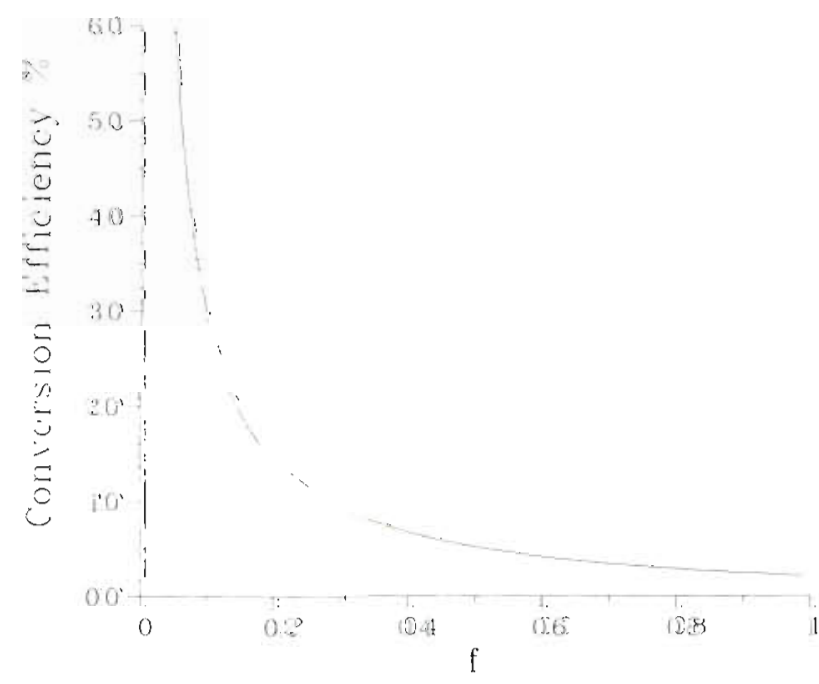

Fig. 2. Implied photosynthetic conversion efficiency as a function of annually averaged $f$-ratio at Station $S$ in the Sargasso Sea, assuming that new production is $5 \mathrm{~mol} \mathrm{O}_{2} \mathrm{~m}^{-2} \mathrm{yr}^{-1}$ ciency is a steep function of $\langle f\rangle$ for values of $\langle f\rangle$ less than 0.35. For comparison, we note that the highest short-term yields recorded in sugarcane fields are $<5 \%$, with average field-crop yields 10 times less (Radmer \& Kok 1977). Efficiencies much higher than about $0.5 \%$, averaged over the year, for opticallydilute suspensions of phytoplankton in a nutrientlimited ocean do not seem plausible. Considerations of ecological energetics therefore favour a value of $\langle f\rangle=$ 0.4 or higher for the Sargasso Sea north of Bermuda, using a figure (Jenkins \& Goldman 1985) of $5 \mathrm{~mol} \mathrm{~m}^{-2}$ $\mathrm{yr}^{-1}$ for $P_{\text {new }}$. This calculation should be treated as a first approximation only: it can be refined as the data on which it is based are improved.

The magnitude of $\langle f\rangle$ can also be related to empirical data for the Redfield ratio connecting biologicallymediated changes in oxygen and carbon in the ocean. If the respiratory quotient in the aphotic zone is equal and opposite to the photosynthetic quotient $(P Q)$ in the photic zone, they should both estimate the Redfield ratio. $P Q$ should be weighted according to the proportion of $P_{T}$ that is new production:

$$
<P Q>=1.8<f>+1.25(1-<f>)
$$

where the factor 1.8 is characteristic for nitrate metabolism and 1.25 for ammonia metabolism (Williams et al. 1979, Raine 1983). When $\langle f\rangle=0.3,\langle P Q\rangle$ will be equal to 1.42 , a figure consistent with the revised (Takahashi et al. 1985) Redfield ratio for oxygen to carbon of 1.42. This calculation is not acutely sensitive to the magnitude of $\langle f\rangle$, however, and it does depend on the value chosen for the $P Q$ of nitrate metabolism. But if we take the revised Redfield ratio as a given and recast Eq. (5), it does seem to exclude very low values of $\langle f\rangle$ :

$$
\left.0.15=\left(P Q_{\text {nitrate }}-1.25\right)<f\right\rangle .
$$

Decreasing $P Q_{\text {nitrate }}$ for any reason implies that $\langle f\rangle$ has to increase in compensation, such that Eq. (6) could not be satisfied for a very low value of $\langle f\rangle$. A corollary of the difference in $P Q$ for new and regenerated production is that the expected OUR calculated for a given nitrate flux will be at least 1.8/1.42 times higher than would be deduced from the standard Redfield ratio for carbon to nitrogen of 6.6 .

\section{INTERMITTENCY AND SAMPLING}

Chronic undersampling is a fact of life in oceanography. Nevertheless, conclusions are often drawn on the implied premise that the ocean, and the plankton in it. are uniform over large regions and constant in time. In retrospect, we can see that undersampling was at the 
root of difficulties of interpretation in the past, as can be illustrated by re-examination of the problems experienced by Riley (1953) and Steemann Nielsen (1952, 1953) in reconciling their data on primary production in the Sargasso Sea. Steemann Nielsen's argument was based on only 3 stations, none of which were north of Bermuda. Oceanographic conditions change immediately south of this latitude (the subtropical front), winter conditions being characterized on the south side by mixing to no more than $150 \mathrm{~m}$ and on the north side to $400 \mathrm{~m}$ with proportionally higher nutrient content (Menzel \& Ryther 1960). Moreover, Steemann Nielsen's measurements were made in June, which we know to be the least productive month of the year (Platt \& Harrison 1985). The final irony is that the detailed criticism of Riley's Sargasso Sea data was based on Steemann Nielsen's Indian Ocean data.

Riley (1953) and Menzel \& Ryther (1960) have drawn attention to the extreme temporal variability of the Sargasso Sea. Thus Riley: 'It is becoming increasingly clear that large variations occur in subtropical and even in tropical waters, so that we must study oceanic waters as closely as we examine our temperate coastal regions in order to arrive at an accurate estimate of their productivity.' Menzel \& Ryther (1960), in a study of the seasonal cycle north of Bermuda found primary production rates agreeing with the observations of both Riley and Steemann Nielsen, depending on the time of the year. They concluded that The results of this study cannot be taken as 'typical' of the Sargasso Sea or the open ocean in general, since probably neither is as uniform as is generally implied'. This view is supported by remote sensing surveys of phytoplankton blooms off the eastern seaboard of the USA (Brown et al. 1985), and by satellite images of ocean colour for the North Atlantic basin (Esaias et al. 1986). In our own work, we have found considerable variation between days in the primary production of the Sargasso Sea (Fig. 3). The mistake made by both Riley and Steemann Nielsen was to express their results as annual rates when neither had covered the seasonal cycle.

It is against this background of spatial variability and temporal intermittency that we should examine procedures for collection and interpretation of data and criteria for assessing consistency. We should also consider under what circumstances (space and time scales) we can reasonably expect the flux divergences of carbon and oxygen to be equal (Platt \& Harrison 1985), or the steady state assumption to be justified. The answers are by no means clear. For the time scale, it seems that nothing less than the annual scale is plausible. In the vertical, the photic zone fixes the depth scale, but its definition is problematic (Sathyendranath \& Platt 1988, Sathyendranath et al. in press). In the horizontal, the problem is no less acute. We know that mesoscale

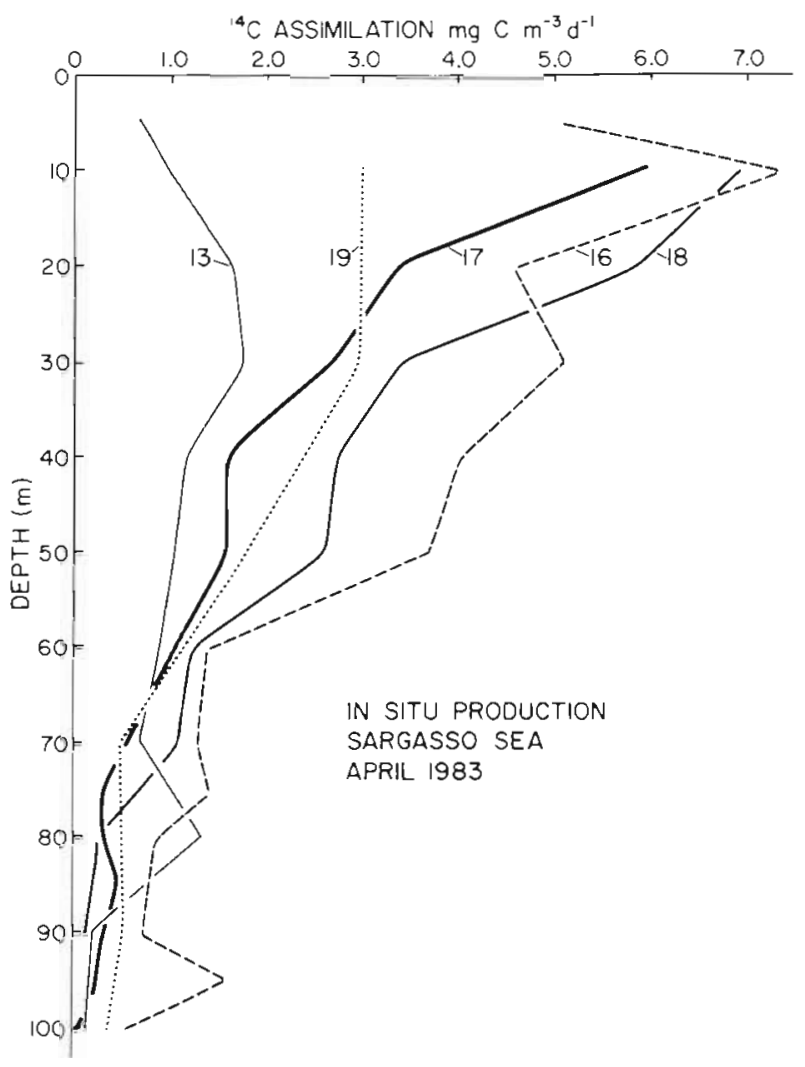

Fig. 3. Variation between days of in situ primary production at the same nominal station in the north Sargasso Sea, April 1983. Water column isothermal over depth range shown. Unpubl. data from Biological Oceanography Division, Bedford Institute of Oceanography, Canada

eddies and other intermittent forcing processes are characteristic features of ocean circulation (Robinson 1983, Sandstrom \& Elliot 1984. Holligan et al. 1985). We have shown that fluctuations in the physical forcing propagate into the biological dynamics in a way that increases the importance of the averaging procedures (Platt \& Harrison 1985). Seasonal fluctuations in oxygen consumption have been found even in the sediment community of the central gyre of the North Pacific at 5900 m depth (Smith \& Baldwin 1984), and highly intermittent sedimentation has been documented at $2000 \mathrm{~m}$ in the North Atlantic (Billet et al. 1983). Thus, the underlying hypothesis of a dynamic steady state for the biogeochemistry of the pelagic region of the ocean is to be considered as no more than an idealisation of a system that, in reality, is perturbed intermittently such that the condition of instantaneous equlibrium is rarely, if ever, attained.

It may be that in the end we shall be defeated by our inability to resolve sufficiently well the distribution of relevant properties in space and time. It may be better to modify the question. Rather than ask, for example, What is the rate of oxygen consumption at depth in the 
ocean?', we might ask 'What is the maximum or minimum OUR that is consistent with the distribution of properties that we are able to observe?' (cf. Emerson 1987). This question would demand that we estimate OUR from explicit box models that would reflect our observational limitations. We would then be able to assign some index of precision to estimates of OUR (cf. Wunsch 1984), essential for a fair test of the hypotheses stated above. Such questions may be addressed through the application of inverse methods to food-web models (Vezina \& Platt 1988).

Bulk property measurements with large, intrinsic space-time scales (Jenkins 1982a) have the advantage that much of the averaging difficulty is removed even before the data are collected. No such bulk property method exists for $P_{T}$. But it is $P_{\text {new }}$ that has been shown in recent studies to be higher than anticipated, and for many applications, $P_{\text {new }}$ is a far more interesting quantity than $P_{T}$, in that it represents the exportable component of primary production. For discussions of the possible role of the ocean biota in absorbing part of the increasing $\mathrm{CO}_{2}$ in the atmosphere, the most relevant component of the carbon fixation is $P_{\text {new }}$. New production represents the so-called 'biological pump' that transports part of the $\mathrm{CO}_{2}$ absorbed from the atmosphere to the sediments (Gammon 1986). Similarly, the new production sets the upper limit to the carbon that can be extracted from the ocean in the form of protein. Far better, in principle, to estimate $P_{\text {new }}$ directly through OUR or sediment traps rather than from $\langle f\rangle$ and $P_{T}$, both of which impose much more demanding sampling requirements. At present, no compilation exists of data on the magnitude and global distribution of new production. On the basis of the (admittedly limited) VERTEX data set, Martin et al. (1987) have calculated a figure of $7.4 \times 10^{9} \mathrm{t} \mathrm{C} \mathrm{yr}^{-1}$ for the new production of the world ocean, using $\langle f\rangle$ values of 0.14 (open ocean); 0.17 (coastal zone); and 0.20 (upwelling areas). The $f$-ratios chosen for coastal and upwelling areas seem too low, but it is instructive to note that even doubling them would have relatively small effect $(<30 \%)$ on the estimate of global new production: the open ocean accounts for $90 \%$ of the total surface area and is therefore weighted strongly in the final answer. Hence the interest in knowing $\langle f\rangle$ for the open ocean as well as possible, and in understanding the processes that conspire to make it so.

It is to be regretted that the significance of $P_{n e w}$ itself has been under-emphasized in favour of inappropriate extrapolations for unjustified comparison with poorly resolved estimates of $P_{T}$. In this respect, the conclusion of Jennings et al. (1984) is significant. They measured the seasonal consumption of nutrients in the water column (an estimate of $P_{\text {new }}$ ) in the Weddell Sea, and compared the results with those for $P_{T}$ measured by ${ }^{14} \mathrm{C}$ uptake. Rather than interpret the outcome (estimate of $P_{\text {new }}$ exceeds that of $P_{T}$ ) as a failing of the ${ }^{14} \mathrm{C}$ method, they concluded that the sampling had been insufficient to resolve the seasonal signal. Implicitly, Hypothesis I was not supported.

\section{FUTURE WORK}

The overriding influence of spatial heterogeneity and temporal intermittency for the dynamics of biological properties in the ocean dictates the sampling strategies that should be striven for in future work. We have emphasized that reliable averages for the long term cannot be calculated if data are lacking on the shortterm variances and covariances. Clearly, synopticity is desirable. One is led inevitably to the conclusion that remote sensing techniques should be employed. However, remote sensing gives direct information only on the pigment biomass. To compute primary production, additional information must be supplied: the irradiance field (Sathyendranath \& Platt 1988), the vertical profile of the pigment biomass (Platt et al. 1988) and the parameters of the photosynthesis-light curve (Sathyendranath \& Platt in press). One possible approach (Platt \& Sathyendranath 1988) is to combine the remotelysensed surface pigment fields with a dynamic biogeography of vertical structure and physiological parameters. Because the computations use photosynthesis parameters determined by the ${ }^{14} \mathrm{C}$ method, remote sensing can contribute nothing to the question of the accuracy of local ${ }^{14} \mathrm{C}$ data. Moreover, the error of estimation by remote sensing will always be greater (lower precision) than can be achieved by direct measurement, tending to limit the power of hypothesis testing at the local scale. On the other hand, at the regional scale, estimates of primary production should be superior to those scaled up from a limited number of shipboard observations at discrete stations, given the rich information on the horizontal structure of the biomass field (Platt \& Herman 1983, Platt \& Sathyendranath 1988).

The question 'What is the primary production in the open ocean?' has no simple answer. Primary production varies in space and time even in the open ocean, and may, at particular times and places, be surprisingly high. Considerable work will be required to develop a reliable global average. Remote sensing has potential to give information only about $P_{T}$. No electromagnetic principle is known that could be exploited to measure $P_{\text {new. }}$. Where the interest is in $P_{\text {new }}$ a weighted integral for $\left(f \cdot P_{T}\right)$ has to be evaluated. There is some possibility that $f$ may be estimated in a semi-quantitative manner from the rate of change of chlorophyll in serial remote sensing images (Lohrenz et al. 1988). Sudden, local increases in biomass would provide circumstantial evi- 
dence of additions of new nitrogen, and therefore of locally-elevated $f$-ratio. Similarly, comparing ocean colour images with thermal images should reveal local, negative, temperature anomalies and provide evidence of enhanced vertical mixing, and therefore of locallyincreased $f$-ratio.

On the basis of tests made so far, no compelling case has been made for support of either Hypothesis I or II, but we should continue to keep an open mind to both possibilities. Future tests should be made with far more rigour than in the past, given the importance of the answer (Platt \& Harrison 1986). The larger $\langle f\rangle$, the more highly resolved must be the data for testing Hypothesis II. It will be necessary to give a clear statement of the probable error associated with each element of the comparison, including systematic as well as random errors. Where a large upward revision of primary production is advocated, it should be shown that the revised figures would not imply violation of known conservation laws (Platt et al. 1984, Laws et al. 1987). Compatibility of time and space scales should be demonstrable in the data sets being compared. Where the comparison is between oxygen and carbon fluxes, it should first be shown that the local flux divergences can be expected to be equal, which may necessitate consideration of interannual fluctuations (Jenkins 1982b, Jenkins \& Goldman 1985, Barber \& Chavez 1986, Deuser 1986). Fair tests of either hypothesis can only be made where well-resolved ${ }^{14} \mathrm{C}$ data exist for the site in question: out-of-date, global summaries will not do. It may have been premature to have attempted a final statement about phytoplankton production when we are still learning important new facts about phytoplankton biomass (Chisholm et al. 1988, Li \& Wood 1988).

If comparison of in vitro and bulk property estimates of ocean productivity has led to a lively and fruitful debate in the literature, the consensus that does seem to be emerging is on a somewhat different point: that the level of new production in the open ocean is higher than previously thought. It is in their contribution to this issue that the real value of the work of Reid \& Shulenberger, Jenkins \& Goldman and Platt \& Harrison is to be found, rather than in evaluation of the various methods for measuring production of plant material in the ocean. In parallel, a consensus is emerging that the elevated new production is a direct consequence of intermittency in the physical forcing of the pelagic ecosystem. On a longer time scale $\left(10^{4} \mathrm{yr}\right)$, variations in new production due to variation in new nitrogen, and consequent feedback to atmospheric $\mathrm{CO}_{2}$ concentration are believed to account for the advance and retreat of glaciers during the ice ages (McElroy 1983 , Bamola et al. 1987). It is towards understanding the details of the biological response to fluctuations in the environment, the adjustments of the structure and dynamics of the food web, that future work should be directed. Above all, it will require an integrated study by physical and biological oceanographers.

Acknowledgements. We thank Prof. K. Banse, Dr A. R. Longhurst and Prof. P. J. leB. Williams for helpful comments.

\section{LITERATURE CITED}

Altabet, M. A., Deuser, W. G. (1985). Seasonal variations in natural abundance of ${ }^{15} \mathrm{~N}$ particles sinking to the deep Sargasso Sea. Nature, Lond. 315: 218-219

Barber, R. T., Chavez, F. P. (1986). Ocean variability in relation to living resources during the 1982-83 El Niño. Nature, Lond. 319: 279-285

Barnola, J. M., Raynaud, D., Korotkevich, Y. S., Lorius, C. (1987). Vostok ice core provides 160,000-year record of atmospheric $\mathrm{CO}_{2}$. Nature, Lond. 329: 408-414

Betzer, P. R., Showers, W. J., Laws, A., Winn, C. D., DiTullio, G. R., Kroopnick, P. M. (1984). Primary productivity and particle fluxes on a transect of the equator at $153^{\circ} \mathrm{W}$ in the Pacific Ocean. Deep Sea Res. 31. 1-11

Billet, D. S. M., Lampitt, R. S., Rice, A. L., Mantoura, R. F. C. (1983). Seasonal sedimentation of phytoplankton to the deep-sea benthos. Nature. Lond. 302: 520-522

Brown, O. B., Evans, R. H., Brown, J. W., Gordon, H. R., Smith, R. C., Baker, K. S. (1985). Phytoplankton blooming off the U.S. East Coast: a satellite description. Science 229: 163-167

Carpenter, E. J., Capone, D. G. (eds.) (1983). Nitrogen in the marine environment. Academic Press, New York

Cheney, R. E., Marsh, J. G., Beckley, B. D. (1983). Global mesoscale variability from collinear tracks of SEASAT altimeter data. J. geophys. Res. 88: 4343-4354

Chisholm, S. W., Olson, R. J., Zettler, E. R., Goericke, R. Waterbury, J. B., Welschmeyer, N. A. (1988). A novel freeliving prochlorophyte abundant in the oceanic photic zone. Nature, Lond. 334: 340-343

Coale, K. H., Bruland, K. W. (1987) Oceanic stratified euphotic zone as elucidated by ${ }^{234} \mathrm{Th}:{ }^{238} \mathrm{U}$ disequilibria. Limnol. Oceanogr. 32: 189-200

Craig, H., Hayward, T. (1987). Oxygen supersaturation in the ocean: biological versus physical contributions. Science 235: 199-202

Dantzler, H. L. Jr. (1977). Potential energy maxima in the tropical and subtropical North Atlantic. J. phys. Oceanogr 7. $512-519$

Deuser, W. G. (1986). Seasonal and interannual variations in deep-water particle fluxes in the Sargasso Sea and their relation to surface hydrography. Deep Sea Res. 33: 225-246

Deuser, W. G., Ross, E. H., Anderson, R. F. (1981). Seasonality in the supply of sediment to the deep Sargasso Sea and implications for the rapid transfer of matter to the deep ocean. Deep Sea Res. 28A (5): 495-505

Dugdale, R. C. (1986). Factors affecting the proportion of new primary production in California Coastal upwelling systems. EOS 67: 994

Dugdale, R. C., Goering, J. J. (1967). Uptake of new and regenerated forms of nitrogen in primary productivity. Limnol. Oceanogr 12: 196-206

Emerson, S. (1987). Seasonal oxygen cycles and biological new production in surface waters of the subarctic Pacific Ocean. J. geophys. Res. 92: 6535-6544 
Emery, W J. (1983). On the geographical variability of the upper level mean and eddy fields in the North Atlantic and North Pacific. J. phys. Oceanogr 13: 269-291

Eppley, R. W (1980). Estimating phytoplankton growth rates in oligotrophic oceans. In: Falkowski, P. G. (ed.) Primary productivity in the sea. Plenum Press, New York, p. 231-242

Eppley, R. W., Peterson, B. W. (1979). Particulate organic matter flux and planktonic new production in the deep ocean. Nature, Lond. 282: 677-680

Eppley, R. W., Renger, E. H. (1988). Nanomolar increase in surface layer nitrate concentration following a small wind event. Deep Sea Res. 35: 1119-1125

Eppley, R. W., Renger, E. H., Venrick, E. L., Mullin, M. (1973). A study of plankton dynamics and nutrient cycling in the central gyre of the North Pacific Ocean. Limnol. Oceanogr. 18 (4): 534-551

Esaias, W E., Feldman, G. C., McClain, C. R., Elrod, J. A. (1986). Monthly satellite-derived phytoplankton pigment distribution for the North Atlantic Ocean Basin. EOS 67 : 835-837

Fogg, G. E. (1982). Nitrogen cycling in sea waters. Phil. Trans. R. Soc. Lond. B296: 511-520

Franks, P. J. S., Wroblewski, J. S., Flierl, G. R. (1986). Prediction of phytoplankton growth in response to the frictional decay of a warm-core ring. J. geophys. Res. 91 (c6): 7603-7610

Gammon, R. H. (1986). Global ocean carbon research program. Committee on Climate Changes and the Ocean, Paris

Garside, C. (1985). The vertical distribution of nitrate in open ocean surface water Deep Sea Res. 32: 723-732

Glover, H. E., Prézelin, B. B., Campbell, L., Wyman, M., Garside, C. (1988). A nitrate-dependent Synechococcus bloom in Sargasso Sea water. Nature, Lond 331: 161-163

Harrison, W. G., Platt, T., Lewis, M. R. (1987). F-ratio and its relationship to ambient nitrate concentration in coastal waters. J. Plankton Res. 9: 235-248

Holligan, P. M., Pingree, R. D., Mardell, G. T. (1985). Oceanic solitons, nutrient pulses and phytoplankton. Nature, Lond. 314: $348-350$

Honjo, S. (1982). Seasonality and interaction of biogenic and lithogenic particulate flux at the Panama Basin. Science 218: $883-884$

Honjo, S. (1984). Global ocean flux study. Proceedings of a Workshop. National Academy Press, Washington, D.C., p. $306-324$

Iverson, R. L. (1977). Mesoscale oceanic phytoplankton patchiness caused by hurricane effects on nutrient distribution in the Gulf of Mexico. In: Andersen, N. R., Zahuranec, B. J. (eds.) Ocean sound scattering prediction. Plenum Press, New York, p. 767-778

Izdar, E., Konuk, T., Honjo, S., Asper, V., Manganini, S., Degens, E. T., Ittekot, V., Kempe, S. (1984). First data on sediment trap experiment in Black Sea deep water. Naturwissenschaften 71: 478-479

Jenkins, W J. (1982a). Oxygen utilization rates in the North Atlantic subtropical gyre and primary production in oligotrophic systems. Nature, Lond. 300: 246-248

Jenkins, W. J. (1982b). On the climate of a subtropical gyre: decade timescale variations in water mass renewal in the Sargasso Sea. J. mar Res. 40: 265-290

Jenkins, W. J. (1988). Nitrate flux into the euphotic zone near Bermuda. Nature, Lond. 331: 521-523

Jenkins, W. J., Goldman, J. C. (1985). Seasonal oxygen cycling and primary production in the Sargasso Sea. J. mar Res. 43: $465-492$
Jennings, J. C., Gordon, L. I., Nelson, D. M. (1984). Nutrient depletion indicates a high primary productivity in the Weddell Sea. Nature, Lond. 309: 51-54

Jerlov, N. G. Steemann Nielsen, E. (1974). Optıcal aspects of oceanography. Academic Press, London

Kerr, R. A. (1985). Long-lived small eddies are crisscrossing the oceans carrying the effects of local mixing hundreds and even thousands of kilometers. Science 230: 793

Knauer, G. A., Martin, J. H., Karl, D. M. (1984). Clobal ocean flux study. Proceedings of a Workshop. National Academy Press, Washington, D.C., p. 136-150

Koblentz-Mishke, O. J., Volkovinsky, V V., Kabanova, J. G. (1970). Plankton primary production of the world ocean. In: Wooster, W. S. (ed.). Scientific exploration of the South Pacific. National Academy of Science, Washington D.C., p. 183-193

Kupferman, S. L., Becker, G. A., Simmons, W. F., Schauer, U., Marietta, M. G., Nies, H. (1986). An intense cold core eddy in the North Atlantic. Nature, Lond. 319: 474-477

Lancelot, C., Billen, G. (1985). Carbon-nitrogen relationships in nutrient metabolism of coastal marine ecosystems. Adv. aquat. Microbiol. 3: 263-321

Laws, E. A., DiTullio, G. R., Redalje, D. G. (1987). High phytoplankton growth and production rates in the North Pacific subtropical gyre. Limnol. Oceanogr. 32: 905-918

LeBouteiller, A. (1986). Environmental control of nitrate and ammonium uptake by phytoplankton in the Equatorial Atlantic Ocean. Mar Ecol. Prog. Ser. 30: 167-179

Lewis, M. R., Harrison, W G., Oakey, N. S., Hebert, D., Platt, T. (1986). Vertical nitrate fluxes in the oligotrophic ocean. Science 234: 870-873

Lewis, M. R., Warnock, R., Irwin, B., Platt, T (1985a). Measuring photosynthetic action spectra of natural phytoplankton populations. J. Phycol. 21: 310-315

Lewis, M. R., Warnock, R., Platt, T (1985b). Absorption and photosynthesis action spectra for natural phytoplankton populations: implications for production in oligotrophic ocean. Limnol. Oceanogr. 30: 794-806

Li, W. K. W (1986). Experimental approaches to field measurements: methods and interpretation. Can. Bull. Fish. Aquat. Sci. 214: 251-286

Li, W. K. W. Wood, A. M. (in press). Vertical distribution of north Atlantic ultraphytoplankton: analysis by flow cytometry and epifluorescence microscopy. Deep Sea Res. 35: 1615-1638

Lohrenz, S. E., Arnone, R. A., Wiesenberg, D. A., DePalma, I. P. (1988). Satellite detection of transient enhanced primary production in the western Mediterranean Sea. Nature, Lond 335: 245-247

Martin, J. H., Knauer, G. A., Karl, D. M., Broenkow, W. W (1987). VERTEX: carbon cycling in the northeast Pacific. Deep Sea Res. 34: 267-285

McCarthy, J. J., Nevins, J. L. (1986). Sources of nitrogen for primary production in warm-core rings 79-E and 81-D1 Limnol. Oceanogr. 31: 690-700

McElroy, M. B. (1983). Marine biological controls on atmospheric $\mathrm{CO}_{2}$. Nature, Lond. 302 (24): 328-329

Menard, Y. (1983). Observations of eddy fields in the northwest Atlantic and northwest Pacific. J. geophys. Res. 88 : 1853-1866

Menzel, D. W. (1974). Primary productivity, dissolved and particulate organic matter and the sites of oxidation of organic matter In: Goldberg, E. D. (ed.) The sea. WileyInterscience, New York, p. 659-678

Menzel, D. W., Ryther, J. H. (1960). The annual cycle of primary production in the Sargasso Sea off Bermuda. Deep Sea Res. 6: 351-367 
Morel, A., Bricaud, A. (1981). Theoretical results concerning light absorption in a discrete medium and applications to specific absorption of phytoplankton. Deep Sea Res. 28: $1375-1393$

National Academy of Sciences (1984). Global Ocean Flux Study. Proceedings of a workshop. National Academy Press, Washington, D.C.

Oakey, N. S. (1982). Determination of the rate of dissipation of turbulent energy from simultaneous temperature and velocity shear microstructure measurements. J. phys. Oceanogr. 12: 256-271

Pace, M. L., Knauer, G. A., Karl, D. M., Martin, J. H. (1987). Primary production, new production and vertical flux in the eastern Pacific Ocean. Nature, Lond. 325: 803-804

Peterson, B. J. (1980). Aquatic primary productivity and the ${ }^{14} \mathrm{CO}_{2}$ method: a history of the productivity problem. Ann. Rev. Ecol. Syst. 11: 369-385

Platt, T (1984). Primary productivity in the central North Pacific: comparison of oxygen and carbon fluxes. Deep Sea Res. 31 (11): 1311-1319

Platt, T., Harrison, W. G. (1985). Biogenic fluxes of carbon and oxygen in the ocean. Nature, Lond 318:55-58

Platt, T., Harrison, W. G. (1986). Reconciliation of carbon and oxygen fluxes in the upper ocean. Deep Sea Res. 33: $273-276$

Platt, T., Harrison, W. G., Horne, E. P. W., Irwin, B. (1987). Carbon fixation and oxygen evolution by phytoplankton in the Canadian high Arctic. Polar. Biol. 8: 103-113

Platt, T., Herman, A. W. (1983). Remote sensing of phytoplankton in the sea: surface-layer chlorophyll as an estimate of water-column chlorophyll and primary production. Int. J. Remote Sensing 4: 343-351

Platt, T., Irwin, B. (1973). Caloric content of phytoplankton Limnol. Oceanogr. 18: 306-310

Platt, T., Lewis, M., Geider, R. (1984). Thermodynamics of the pelagic ecosystem: elementary closure conditions for biological production in the open ocean. In: Fasham, M. J. R (ed.) Flows of energy and materials in marine ecosystems Plenum Press, New York, p. 49-84. NATO Conference Series IV, Marine Sciences 13

Platt, T., Sathyendranath, S. (1988). Oceanic primary production: estimation by remote sensing at local and regional scales. Science 241. 1613-1620

Platt, T., Sathyendranath, S., Caverhill, C., Lewis, M. R. (1988). Ocean primary production and available light: further algorithms for remote sensing. Deep Sea Res. 35: 855-879

Radmer, R., Kok, B. (1977). Photosynthesis: limited yields, unlimited dreams. Bioscience 27.599-605

Raine, R. C. T (1983). The effect of nitrogen supply on the photosynthetic quotient of natural phytoplankton assemblages. Botanica mar 26: 417-423

Redfield, A. C., Ketchum, B. H., Richards, F. A. (1963). In: Hill, M. N. (ed.) The sea. The influence of organisms on the composition of sea-water. Interscience, New York, p. 26-77

Reid, J. L., Shulenberger, E. (1986). Oxygen saturation and carbon uptake near $28^{\circ} \mathrm{N}, 155^{\circ} \mathrm{W}$ Deep Sea Res. 33: $267-271$

Riley, G. A. (1953). Letter to the Editor J. Cons. int. Explor Mer 19: 85-89

Robinson, A. R. (ed.) (1983). Eddies un marine science Springer-Verlag, Berlin

Robinson, A. R., Hecht, A., Pinardi, N., Bishop, J., Leslie,
W. G., Rosentroub, Z., Mariano, A. J., Brenner, S. (1987). Small synoptic/mesoscale eddies and energetic variability of the eastern Levantine basin. Nature, Lond. 327: 131-134

Sandstrom, H. Elliott, J. A. (1984). Internal tide and solitons on the Scotian Shelf: a nutrient pump at work. J. geophys Res. 89: 6415-6426

Sarmiento, J. L., Toggweiler, J. R. (1984). A new model for the role of the oceans in determining atmospheric $p \mathrm{CO}_{2}$ Nature, Lond. 308: 621-624

Sathyendranath, S. Platt, $T$ (1988). The spectral irradiance at the surface and in the interior of the ocean: a model for application in oceanography and remote sensing. J. geophys. Res 93 (C8): $9270-9280$

Sathyendranath, S., Platt, $T$ (in press). Computation of aquatic primary production: extended formalism to include effect of angular and spectral distribution of light. Limnol. Oceanogr

Sathyendranath, S., Platt, T., Caverhill, C. M., Warwick, R. E., Lewis, M. R. (in press). Remote sensing of oceanic primary production: computations using a spectral model. Deep Sea Res.

Shulenberger, E. L., Reid, J. L. (1981). The Pacific shallow oxygen maximum, deep chlorophyll maximum, and primary productivity, reconsidered. Deep Sea Res. 28 A $901-919$

Smith, K. L., Baldwin, R. J. (1984). Seasonal fluctuations in deep-sea sediment community oxygen consumption: central and eastern North Pacific. Nature, Lond. 307: 624-626

Smith, R. E. H., Geider, R. J., Platt, T. (1984). Microplankton productivity in the oligotrophic ocean. Nature, Lond 311 $252-254$

Steemann Nielsen, E. (1952). The use of radioactive carbon $\left({ }^{14} \mathrm{C}\right)$ for measuring organic production in the sea. J. Cons. int. Explor. Mer 18: 117-140

Steemann Nielsen, E. (1953). On organic production in the oceans. J. Cons. int. Explor. Mer 19: 309-367

Sterrer, W., Sands, J., Barbour, G. C. (1981). Bermuda energy future. Bermuda Biological Station for Research, Inc.

Takahashi, T., Broeker, W. S., Langer, S. J. (1985). Redfield ratios based on chemical data from isopycnal surfaces. J. geophys. Res. 90: 6907-6924

Tilzer, M. M. (1983). The importance of fractional light absorption by photosynthetic pigments for phytoplankton productivity in Lake Constance. Limnol. Oceanogr. 28 (5): 833-846

Vezina, A. F., Platt, T (1987). Small-scale variability of new production and particulate fluxes in the ocean. Can. J. Fish. Aquat. Sci 44: 198-205

Vezina, A F., Platt, T (1988). Food-web dynamics in the ocean. I. Best-estimates of flow networks using inverse methods. Mar. Ecol. Prog. Ser. 42: 269-287

Williams, P. J. leB., Raine, R. C. T., Bryan, J. R. (1979). Agreement between the ${ }^{14} \mathrm{C}$ and oxygen methods of measuring phytoplankton production: re-assessment of the photosynthetic quotient. Oceanologica Acta 2: 411-416

Williams, P. J. leB., Heinemann, K. R., Marra, J., Purdie, D. A. (1983). Comparison of ${ }^{14} \mathrm{C}$ and $\mathrm{O}_{2}$ measurements of phytoplankton production in oligotrophic waters. Nature, Lond. 305: $49-50$

Wunsch, C. (1984). An eclectic Atlantic Ocean circulation model. Part I: the meridional flux of heat. J. phys. Oceanogr 14: 1712-1733

Wyrtki, K., Maggard, L., Hagar, J. (1976). Eddy kinetic energy in the oceans. J. geophys. Res. 81 2641-2646

Manuscript received: July 9, 1988

Revised version accepted: November 23, 1988 